\title{
PLATELET RICH FIBRIN VERSUS HYALURONIC ACID AS PALATAL WOUND DRESSINGS FOLLOWING EPITHELIALIZED FREE GINGIVAL GRAFT HARVEST: A RANDOMIZED CONTROLLED CLINICAL TRIAL
}

\author{
Ahmed Abdel Aziz Hassan*, Nourhan Alaa El Din Akl** and Doaa Adel-Khattab ${ }^{* * *}$
}

\begin{abstract}
Introduction: Patient centered outcome became of great interest nowadays. Patient's pain and discomfort following free gingival graft procedure are common complain. Different palatal dressings are suggested to cover and protect the palatal donor site as stents, collagen gelatin scaffolds, platelet rich fibrin (PRF), hyaluronic acid (HA) and Alvogyl. However, in the literature no ideal agent has been emphasized.
\end{abstract}

Objectives: This randomized controlled clinical trial compares for the first-time the effect of PRF versus HA palatal wound dressings on postoperative pain, post-surgical bleeding, and wound healing.

Materials and methods: Following sample size calculation, 30 systemically healthy patients requiring palatal mucosal graft harvesting were randomized to receive either PRF or HA (intervention groups) or gelatin sponge (control group) as palatal dressings. Patient-reported visual analogue score (VAS) pain scores as primary outcome. Post-surgical bleeding and wound healing were considered as secondary outcomes.

Results: VAS pain scores were reported minimal in PRF group throughout follow up intervals, PRF was statistically significant when compared to HA group at 3 and 7 days postoperative, PRF was statistically significant when compared to control group from 3 to 30 days postoperative and VAS in PRF was nearly 0 in day 14. PRF group showed the highest value of healing index during all the follow up intervals with mean 4.4 at 30 days that indicates a full healing of palatal wound area.

Conclusions: Within this study's limitations, PRF had better outcomes than both HA and gelatin sponge in means of cost, pain reduction, hemostasis and healing properties.

KEYWORDS: Platelets rich fibrin, hyaluronic acid, palatal dressing.

\footnotetext{
*Associate Professor of Oral Medicine, Periodontology and Diagnosis, Faculty of Dentistry, Ain Shams University, Egypt ** BDS Faculty of Dentistry Misr International University, MSc Periodontology Department Ain Shams University, Egypt ***Lecturer of Oral Medicine, Periodontology and Diagnosis, Faculty of Dentistry, Ain Shams University, Egypt
} 


\section{INTRODUCTION}

Oral soft tissue healing had a remarkable regenerative ability, it is considered faster than the skin and generates less scar tissue, therefore; intraoral wounds are sometimes considered more like fetal wounds. The intraoral wound healing process is influenced by the presence of large numbers of bacteria and saliva that contains many growth factors such as epidermal growth factor (EGF), basic fibroblast growth factor (FGF), insulin and insulin-like growth factor-1 (IGF-1). ${ }^{(1)}$

Wound healing entails different physiologic phases. The first phase occurs within the first 24 to 48 hours in which epithelial cells travel from wound edges. The second phase of wound healing begins at day 3 and ends at day 5 after the injury, it is characterized by formation of granulation tissue, formation of new capillaries by the budding of endothelial cells present in the surrounding preexisting vessels. The final phase of wound healing starts at day 7 and is characterized by remodelling of newly formed tissues and high collagen synthesis. In addition, granulation tissue gradually remodels into scar tissue for weeks and months until the tissues restore its tensile strength to nearly normal levels. ${ }^{(2)}$

A healthy periodontal apparatus around teeth require adequate zones of attached keratinized gingiva. ${ }^{(3)}$ Free gingival graft (FGG) procedure is one of the most common approaches in mucogingival surgeries who was first introduced by Bjorn 1963. (4) The palate is the most common donor site for it. Gingival grafts harvested with the epithelium can be used either directly as a FGG or as a subepithelial connective tissue graft after de-epithelialization outside the oral cavity to increase the amount of keratinized tissue, increase the vestibular depth, increase the volume of gingival tissues in edentulous spaces, covering roots in areas of gingival recession and increase keratinized tissue around implants. ${ }^{(5,6)}$

FGG surgical wound heals with secondary intention within 2-4 weeks, due to the removal of the epi- thelial layer of the palatal mucosa. It was reported that complete epithelialization of the palatal wound occurs 4 weeks after FGG surgery. ${ }^{(7)}$ Discomfort, pain and bleeding at the donor site are the most common consequences following FGG harvesting. (8) Different agents were suggested to cover and protect the palatal donor site as stents, periodontal packs, collagen gelatin scaffolds, platelet rich fibrin (PRF), hyaluronic acid (HA), Alvogyl and Low level laser therapy. However, no gold standard exists. ${ }^{(7,9-11)}$

PRF was first presented by Choukroun et al. $2000^{(12)}$ as a second-generation platelet concentrate, it is defined as an autologous leukocyte and plateletrich fibrin biomaterial. PRF entails $97 \%$ of total plasma platelets and $50 \%$ of leukocytes and fibrin network that consists of flexible fibrin network which is organized in 3-dimensions that provides elasticity to the PRF. ${ }^{(12,13)}$ Platelets entrapped in PRF release growth factor and cytokines that stimulate angiogenesis, organization maturation of the tissues and inflammation resistance. The growth factors released from PRF that aid in healing are vascular endothelial growth factor (VEGF), insulin like growth factor (IGF) and platelets derived growth factor (PDGF). ${ }^{(14)}$

PRF was investigated as a palatal wound dressing, it showed complete wound closure by the $14^{\text {th }}$ day and patients reported less pain and discomfort post operatively, complete re-epithelization of the palatal wound. PRF showed better results than gelatin sponges and control groups. ${ }^{(15-17)}$

Hyaluronic acid (HA) is a member of a large family of glycosaminoglycans (GAGs), which are the main components of the extracellular matrix. HA is characterized by owning anti-inflammatory, anti-edematous and anti-bacterial effects. ${ }^{(18)}$

HA has an important part in wound healing, it possesses a role in the migration and adherence of polymorph nuclear leucocytes and macrophages at the inflamed site and phagocytosis of invading 
microbes, promotes cell proliferation, migration of cells into granulation tissue matrix and granulation tissue organization. ${ }^{(18)}$

Yildrim et al. $2018^{(19)}$ performed a study that evaluated the effect of two different concentrations $(0.2 \& 0.8 \%)$ of topical HA on post-operative patient discomfort and wound healing of palatal donor sites following FGG. The study concluded a significant complete epithelization and post-operative pain reduction in patients treated with $0.2 \% \mathrm{HA}$ gel. ${ }^{(19)}$

Considering the high demand to target the patient centered outcomes, this study attempted to minimize patient's pain and discomfort after FGG procedure, platelets rich fibrin versus hyaluronic acid as a palatal wound dressing were investigated on the incidence and severity of postoperative pain, post-surgical bleeding and palatal wound healing following epithelialized free gingival graft harvesting in a randomized controlled clinical trial.

\section{MATERIAL AND METHODS}

\section{Experimental study}

This study was designed as a prospective, randomized, and controlled clinical trial with a parallel design, to investigate the effects of PRF (intervention group) versus $\mathrm{HA}$ with gelatin sponge (intervention group) and gelatin sponge (control group) as palatal wound dressing agents, on the incidence and severity of postoperative pain, post-surgical bleeding, and palatal wound healing following epithelialized free gingival graft harvesting. This randomized controlled trial was approved by the ethical committee of the Faculty of Dentistry, Ain Shams University (approval number (FDASU-RECR 121566) and was registered on www.clinicaltrials.gov (registration number (NCT04390100).

\section{Sample size and characteristics}

The study consisted of three groups; the number of patients in each group was determined by sample size calculation based upon the results of Sharma et al. $2018^{(20)}$, that had 10 patients in each group in the study. Using alpha level of $0.05(5 \%)$ and $\beta$ level of $0.20(20 \%)$ i.e. power $=80 \%$; the estimated minimum required sample size was approximately 10 cases in each group. Sample randomization was done using computer-generated random numbers (www.randomizer.org). Patients were randomized into either intervention groups PRF and HA or control group. Allocation concealment was achieved using a sealed coded opaque envelope containing treatment of the subject.

\section{Inclusion criteria}

Patients enrolled in this study who required a soft tissue augmentation procedure with FGG or deepithelized FGG as coverage of gingival recession, vestibuloplasty, increasing zone of keratinized tissue around implants. Good patient compliance with plaque control instructions following initial therapy. Nonsmoker and systemically free patients according to (American Society of Anesthesiologists I. ${ }^{(21)}$

\section{Preoperative phase}

Following the verbal and written explanation of the surgical procedure, all patients received full mouth supra- and subgingival scaling and detailed oral hygiene instructions.

\section{Surgical procedure}

The primary surgical site requiring soft tissue grafting was prepared. Dimensions of the graft were determined and transferred to a tin foil template in the required shape and size (Fig. 1a). The palatal donor site was anesthetized by $0.3 \mathrm{ml}$ of a solution of $4 \%$ articain $^{\circ}$ and $0.001 \%$ adrenalin. FGG was

\footnotetext{
* Alexandria Company for Pharmaceutical \& Chemical Industries, Egypt.
} 
harvested as previously described by Bjorn $1963^{(4)}$, an aluminum foil template of the recipient site was made and placed over the donor site, the incision was made to harvest the FGG from the palate according to aluminum template. The harvested FGG was approximately 2-mm thickness of epithelium and a thin layer of connective tissue. FGG thickness and width was measured. Palatal dressings were applied either PRF or HA loaded on gelatin sponge, in control group only gelatin sponge was applied.

In PRF group, just prior to surgery a $10 \mathrm{ml}$ intravenous blood was obtained from the median antecubital vein of the patient in $10 \mathrm{ml}$ glass tubes* without additives to be centrifuged immediately at 3000 RPM for 10 minutes at room temperature..$^{(12)}$ Three parts quickly appear in the tube, a packed red blood cell at the bottom, acellular plasma at top and the PRF clot in between. The PRF clot was removed from the tube using sterile tweezers, separating it from the RBC base by using a surgical blade; the clot was then placed in the PRF box to obtain a membrane. The PRF membrane was placed as a palatal dressing and fixed in place by $\mathrm{X}$ suture using 5-0 polypropylene.**

In HA group, gelatin sponge was cut according to the graft's dimensions to act as a carrier for the HA ${ }^{\cdots \cdot}$ that was used as a palatal dressing. Gelatin sponge was then fixed in place using X suture. Patients were instructed to apply it four times daily for 14 days. In the control group, only gelatin sponge was sutured in the donor site.

\section{Postoperative care:}

Every patient was administered $1 \mathrm{~g}$ amoxicillin and clavulanic acid ${ }^{* * * *}$ (twice a day for 5 days and $150 \mathrm{mg}$ biprofenid ${ }^{* * * * *}$ when needed. Patients were advised to rinse twice a day with $0.12 \%$ chlorhexidine HC solution ${ }^{* * * * * *}$ for 3 weeks following the surgery. Sutures were removed 14 days following the surgery.

\section{Subjective assessment}

Visual analogue score (VAS) of Pain were assessed, patients were asked to assess their pain sensation at $1^{\text {st }}, 3^{\text {rd }}, 7^{\text {th }} 14^{\text {th }} 21^{\text {st }}$ and $30^{\text {th }}$ days using the visual analogue scale (VAS) ${ }^{(22)}$, the. The VAS of pain was scored on a scale ranged from 0 (no pain) to 10 (severe pain). VAS of Bleeding was assessed that patients were asked to report the presence of bleeding at $1^{\text {st }}, 3^{\text {rd }}, 7^{\text {th }} 14^{\text {th }} 21^{\text {st }}$ and $30^{\text {th }}$ days using VAS of bleeding. VAS of bleeding was recorded from 0 till 4; 0: no bleeding, 1: oozing, 2: accidental low bleeding, 3 : continuous low bleeding and 4: massive bleeding. The long follow up was in accordance to Sousa et al. $2020^{(23)}$ that monitored VAS for patients after FGG until 30 and 90 days postoperative.

\section{Objective assessment:}

The Healing index scale by Landry et al., $1988^{(24)}$ was used to assess the palatal wound healing, where in this index tissue color, response to palpation, presence of granulation tissue, presence of suppuration and epithelization of the incision margin were recorded. The healing index has 5 grades which are 5(excellent healing), 4(very good healing), 3 (good healing), 2(poor healing) and 1(very poor healing). Photographs of the palatal wound were taken, and healing index was assessed at $7^{\text {th }}, 14^{\text {th }}, 21^{\text {st }}$ and $30^{\text {th }}$ days. The area of the wound

\footnotetext{
* Dry Vacutube, Biocon $®$, Brazil.

** Assut Sutures, Switzerland.

*** Gengiegel $0.2 \%$ oral gel $20 \mathrm{ml}$ Riceerfarma, Italy.

**** GlaxoSmithKline, Cairo, Egypt.

***** Sanofi Aventis, Cairo, Egypt.

****** Hexitol, The Arab Drug Company, Cairo, Egypt.
} 
was assessed by taking photographs of the palatal wound where the UNC 15 periodontal probe $e^{* * * * * * *}$ was used to standardize the measures at $3^{\text {rd }}, 7^{\text {th }}, 14^{\text {th }}$, $21^{\text {st }}$ and 30 th days and the area of palatal wound was assessed using Image $\mathrm{J}$ program, the wound area was calculated by selecting the Freehand selections tool on image $\mathrm{j}$, then tracing the wound margin and analyzing it in $\mathrm{mm}^{2}$.

\section{Statistical analysis:}

Data were presented as frequencies and percentages and were analyzed using chi square test. Numerical data were tested for normality using Shapiro-Wilk test and were presented as mean and standard deviation values. Parametric data were analyzed using one-way ANOVA followed by Tukey's post hoc test for intergroup comparisons and one-way repeated measures ANOVA followed by Bonferroni post hoc test for intragroup comparisons. Non-parametric data were analyzed using Kruskal-wallis test followed by pairwise comparisons utilizing Mann Whitney U test with Bonferroni correction for intergroup comparisons and Friedman's test of repeated measures followed by multiple pairwise comparisons utilizing Wilcoxon signed-rank test with Bonferroni correction for intragroup comparisons. The significance level was set at $\mathrm{p} \leq 0.05$ within all tests. Statistical analysis was performed with using IBM SPSS ${ }^{* * * * * * * *}$ advanced statistics.

\section{RESULTS}

\section{Demographic data}

This study was conducted on (30) participants that were randomly allocated to 3 groups i.e. (10) participants each. 6 (60\%) the cases in PRF group were females and 4 (40\%) were males. In HA group and control (C) group, 7 (70\%) of the cases were females while $3(30 \%)$ were males. The mean age of the cases in PRF was (30.90 \pm 7.53$)$, for HA was (35.10 \pm 7.09$)$, while for control group was (34.90 \pm 8.18$)$. There was no significant difference in gender and age distribution in both groups $(\mathrm{p}=0.861$ and 0.393 ) respectively.

PRF showed the best healing throughout the follow up intervals than HA and control groups (Fig.1).

Regarding the VAS of pain, at day 1 postoperative the highest pain score was presented in control group (9.8) which represents severe unbearable pain, HA showed pain score 7 that represent very intense pain, PRF had the least value of 5.3 that represent moderate pain, both PRF and HA were statistically significant than control group $(p<0.001)$. At day 3 and 7 days postoperative the pain was minor in PRF group $(3,1.7)$, moderate in HA (6) and severe (7) in control with statistically significant difference between PRF and both HA and control $(\mathrm{p}<0.001)$. At 14 and 21 days postoperative the pain was very mild in PRF $(0.6,0.2)$, mild in HA $(2.3,1.5)$ and moderate in control group (5.2, 3.6), control group showed significantly higher than values of PRF and HA groups $(\mathrm{p}<0.001)$. At 30 days postoperative, PRF showed no pain (0), HA had minimal pain (0.7) and control had minor pain (1.5), control showed to be significantly higher than PRF group $(\mathrm{p}<0.001)$. Intragroup comparisons showed statistically significant difference in PRF and HA groups between 1 day to 21 and 30 days postoperative, however, control group show only statistically significant between 1 day and 30 days postoperative $(\mathrm{p}<0.001)$ (Table 1$)$. 


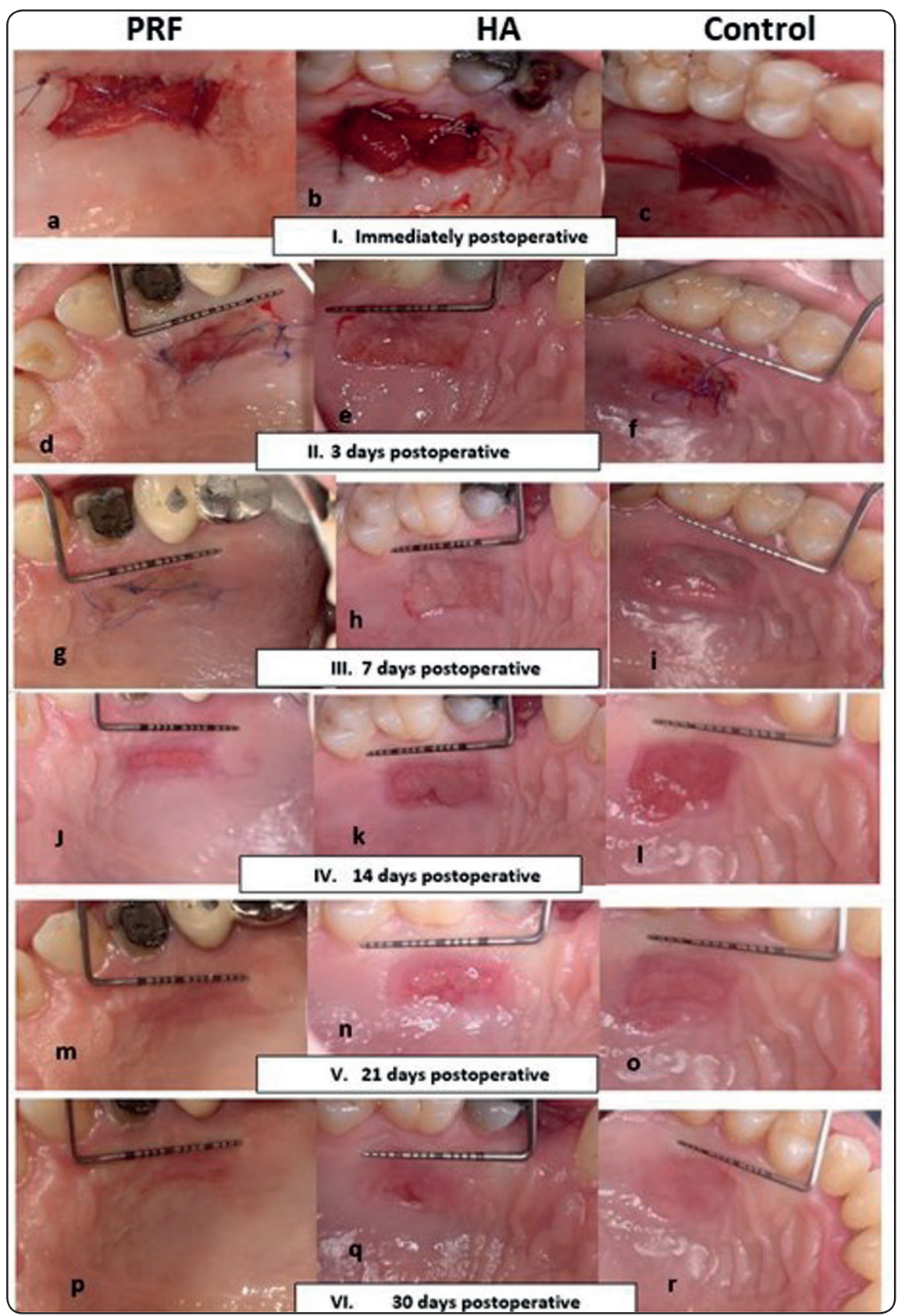

Fig. (1) Clinical palatal wound healing of PRF, HA and control groups. I. immediately postoperative, II. 3 days, III. 7 days, IV. 14 days, V. 21 days and VI. 30 days postoperative. a, d, g, J, m, p. different healing intervals for PRF, b, e, h, k, n, q. different healing intervals for HA, c, f, i, l, o, r. different healing intervals for control group. 
TABLE (1) Mean and standard deviation (SD) values for (VAS) scores in different groups. Different superscript letters indicate a statistically significant difference, comparisons between groups in horizontal row is represented by capital letters, vertical column indicates the difference within the same group represented by small letters. ***; Extremely significant $(\mathrm{p}<0.001) * *$; Highly significant $(0.001<\mathrm{p}<0.01) *$; significant $(0.01<\mathrm{p} \leq 0.05) \mathrm{ns}$; non-significant $(\mathrm{p}>0.05)$

\begin{tabular}{ccccc}
\hline Follow-up & PRF & HA & C & p-value \\
\hline $\mathbf{1}$ Day & $5.0 \pm 1.89^{\mathrm{B}, \mathrm{a}}$ & $7.00 \pm 2.94^{\mathrm{B}, \mathrm{a}}$ & $9.80 \pm 0.42^{\mathrm{A}, \mathrm{a}}$ & $\mathbf{0 . 0 0 1} * *$ \\
$\mathbf{3}$ days & $3.30 \pm 1.64^{\mathrm{B} \text { ab }}$ & $6.20 \pm 1.93^{\mathrm{A}, \mathrm{a}}$ & $7.50 \pm 1.51^{\mathrm{A}, \mathrm{ab}}$ & $<\mathbf{0 . 0 0 1} * * *$ \\
$\mathbf{7}$ days & $1.70 \pm 2.26^{\mathrm{B}, \mathrm{abc}}$ & $6.10 \pm 2.23^{\mathrm{A}, \mathrm{a}}$ & $7.10 \pm 1.20^{\mathrm{A}, \mathrm{ab}}$ & $<\mathbf{0 . 0 0 1} * * *$ \\
$\mathbf{1 4}$ days & $0.60 \pm 0.52^{\mathrm{B}, \mathrm{cd}}$ & $2.30 \pm 1.77^{\mathrm{B}, \mathrm{ab}}$ & $5.20 \pm 0.79^{\mathrm{A}, \mathrm{bc}}$ & $<\mathbf{0 . 0 0 1 * * *}$ \\
$\mathbf{2 1}$ days & $0.20 \pm 0.63^{\mathrm{B}, \mathrm{d}}$ & $1.50 \pm 1.27^{\mathrm{B}, \mathrm{b}}$ & $3.60 \pm 0.97^{\mathrm{A}, \mathrm{d}}$ & $<\mathbf{0 . 0 0 1} * * *$ \\
$\mathbf{3 0}$ days & $0.00 \pm 0.00^{\mathrm{B}, \mathrm{d}}$ & $0.70 \pm 0.67^{\mathrm{AB}, \mathrm{b}}$ & $1.50 \pm 0.85^{\mathrm{A}, \mathrm{b}}$ & $<\mathbf{0 . 0 0 1 * * *}$ \\
$\mathbf{p}-\mathbf{v a l u e}$ & $<\mathbf{0 . 0 0 1} * * *$ & $<\mathbf{0 . 0 0 1 * * *}$ & $<\mathbf{0 . 0 0 1 * * *}$ &
\end{tabular}

Regarding the VAS of bleeding there was no significant difference between values of different groups at 1 and 3 days $(\mathrm{p}=0.547)$. At $7,14,21$ and 30 days all groups had a score of (0). In PRF group showed statistically higher value measured at day 1 than values measured at other follow up intervals $(\mathrm{p}<0.001)$, in HA group 1 and 3 days were significantly higher than values measured at other follow up intervals $(\mathrm{p}<0.001)$, control group measured at day 1 to be significantly higher than values measured at other follow up intervals $(\mathrm{p}<0.001)$ (Fig. 2).

The healing index results revealed that PRF group had the highest healing values in all intervals. There was a significant difference between PRF to the other groups at 7,14 and 21 days $(\mathrm{p}<0.001)$. At 30 days the highest value was found in PRF group
(4.40 \pm 0.70$)$, followed by HA group $(4.00 \pm 0.00)$, while the lowest value was found in control group (3.80 \pm 0.42$)$. Pairwise comparisons showed value of PRF group to be significantly higher than that of control group $(\mathrm{p}<0.001)$ (Fig.3).

The wound surface area results showed that there was no significant difference between values of different groups $(\mathrm{p}=0.325)$ at day 3 , the highest value was found in group HA group $(93.62 \pm 15.06)$, followed by control group $(91.35 \pm 7.72)$, while the lowest value was found in PRF group $(80.43 \pm 32.99)$. At 7 and 14 days there were a significant difference between PRF and HA groups $(\mathrm{p}<0.001)$. At 21 and 30 days there were a statistically significantly between PRF and control group $(\mathrm{p}<0.001)$, the smallest wound area was present in PRF group at 30 days followed by HA then control group (Fig. 4). 


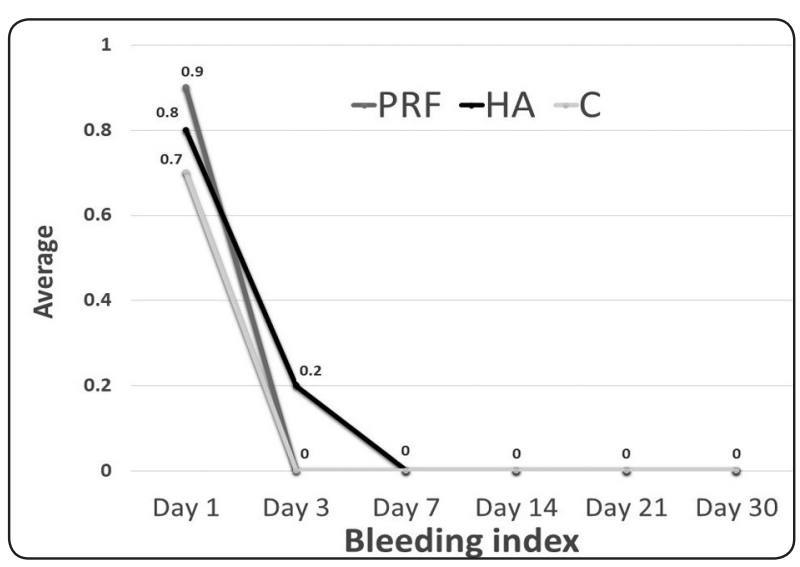

Fig. (2) Line chart showing mean values of bleeding index in PRF, HA and control groups.

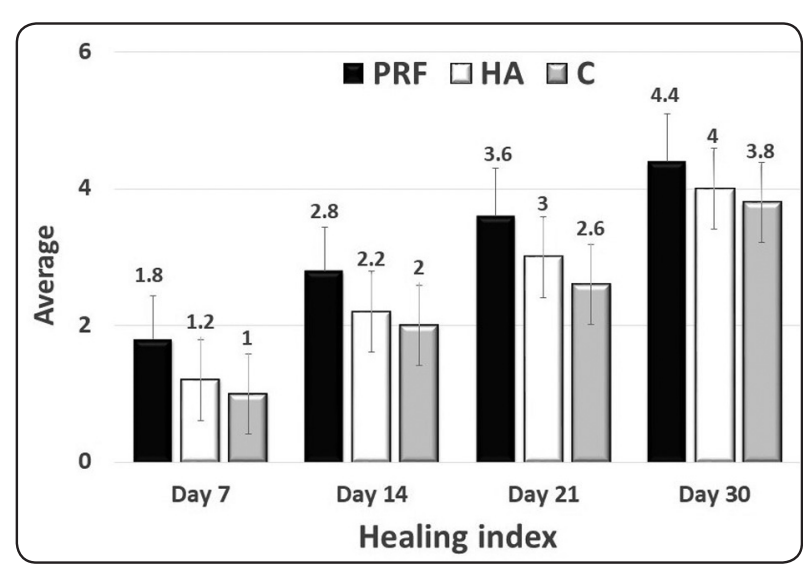

Fig. (3) Bar chart showing mean and standard deviation values of healing index in PRF, HA and control groups.

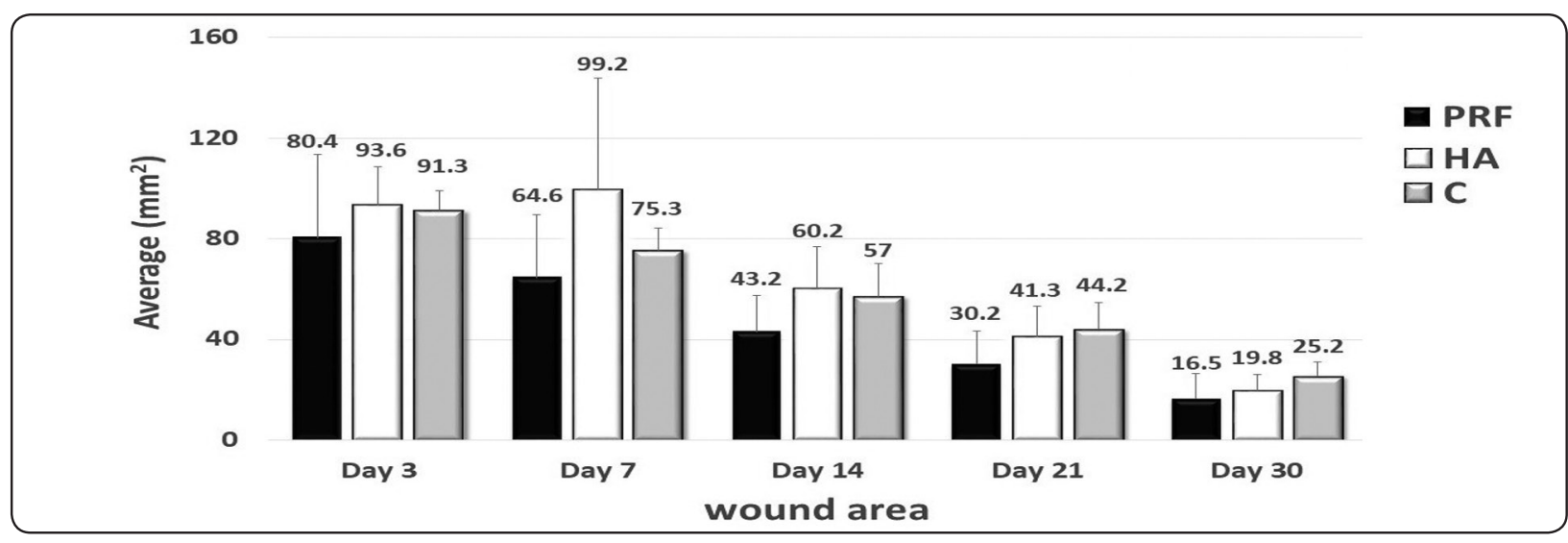

Fig. (4) Bar chart showing mean and standard deviation values of wound surface area (mm2) in PRF, HA and control groups.

\section{DISCUSSION}

After harvesting FGG from the palate, postoperative pain and bleeding are the most side effects. ${ }^{(25,26)}$ A variety of dressing materials have been proposed to protect the palatal wound donor site, rendering it more comfortable, accelerating its re-epithelialization process and to protect the palatal connective tissue. (27) The present randomized controlled trial tested for the first time the comparison between PRF and hyaluronic acid following the harvesting of a free gingival graft.

In this study PRF was used as a palatal dressing after FGG procedure since it is cheap, totally safe as it is obtained from patient's own blood. PRF constitutes of fibrin network, platelets and growth factors. The fibrin network entangles circulating stem cells at the wound site. Furthermore, VEGF, IGF-1 and PDGF are the growth factors produced from PRF that play an important role in healing, as they regulate cell migration, proliferation, and survival of mesenchymatous cell lineage. In addition, stimulation of mitogenesis, angiogenesis and macrophage activation. ${ }^{(13,28)}$

HA was used in this study as a palatal dressing after FGG procedure, limited available data is 
present regarding HA as dressing following FGG. However, HA has potent anti-inflammatory and anti-edematous characteristics as it accelerates tissue healing. Furthermore, HA binds to fibrin within the wound forming a matrix which acts as a scaffold through which the peripheral neutrophils, monocytes, macrophages and fibroblasts migrate into the wound to initiate granulation tissue formation. ${ }^{(18)}$ The control group in this study was gelatin sponge a thermally denaturated collagen of bovine or porcine origin. ${ }^{(29)}$ Due to its remarkable hemostatic properties, absorbable gelatin sponge has been advocated as a standard wound dressing material. ${ }^{(1)}$

Regarding the results of VAS of pain, PRF had only a moderate pain score at day 1 postoperative, from 3 to 7 days PRF showed a mild pain, with minimal pain at 14, 21 days and no pain at 30 days. However, HA had a severe pain at 1-day postoperative, moderate pain from 3 to 14 days and mild pain in 21 and 30 days. Regarding the control group pain score was severe from 1 to 7 days postoperative, moderate at 14 and 21 days, mild at 30 days. In addition, there were an extreme statistically significant difference regarding VAS at 3 and 7 days between PRF and the other two groups. Hyaluronic acid had an effect on the fourteen day. At 14, 21 days both PRF and HA had a significant decrease in pain than control group. At 30 days only PRF had a statistically decrease in pain than control group.

The superior results of PRF regarding pain control may be due to that PRF stimulates wound healing through the outburst release of growth factors such as PDGF, IGF-1, and VEGF until its dissolution by day 14. In addition, patients in HA reported that they did not follow the instructions properly to apply HA four times a day for 14 days postoperative. These results were in accordance with Sousa et al. $2020^{(23)}$ who assessed VAS of pain, at 2, 7 and 14 days and showed that there was statistically significant difference between the
A-PRF group and the gelatin sponge group. At day 30 and 90 there was no statistically significant difference between both groups. Yildrim et al $2018^{(19)}$ conducted that $0.2 \%$ HA showed less pain than the control group on day 7 .

Regarding the VAS of bleeding, there were no statistically significant difference between the three groups, all the 3 groups had o bleeding by 7 day. This may be due to applied pressures from suturing in the three groups. About healing index PRF had the highest scores than HA and control groups, at 7 days only control had a very poor healing, PRF and HA had a poor healing, at 30 days postoperative PRF showed healing index of 4.4 score which represent approximately complete wound healing and epithelization. HA had a very good healing and control group had only a good healing. This may be due to the ability of PRF that enhances wound healing through the fibrin meshwork formation that supports blood clot and promotes rapid reepithelization. These results were in accordance with a study, which concluded that the healing of the PRF group showed higher results than control group. ${ }^{(30)}$

PRF revealed the least wound area all over the follow up intervals, this may be due to the growth factors released from PRF which stimulates rapid epithelization and wound healing. These results were in accordance with a study that compared PRF and oxidized regenerated cellulose as palatal dressings after FGG harvesting. The area of the wound was measured by taking photographs and using computer program. It concluded that day 7 , there was a similar reduction in size between groups while there was no significant difference between wound areas at day $14 .^{(31)}$

Collectively, within the current randomized controlled trial limitations, PRF had revealed a superior outcome than hyaluronic acid and collagen sponge as a practical palatal dressing agent, in hemostasis, pain reduction, and palatal wound healing. 


\section{CONCLUSION}

PRF showed superior results regarding pain control and wound healing than hyaluronic acid or gelatin sponge. PRF is a practical palatal surgical dressing regarding cost, pain reduction, hemostasis, and healing properties.

\section{Statement of Conflict of Interest}

The authors declare that they have no conflicts of interest.

\section{REFERENCES}

1. Von Den Hoff JW, Maltha JC, Kuijpers-Jagtman AM. Cleft Lip and Palate: Palatal Wound Healing: The Effects of Scarring on Growth. 2006; 301-313.

2. Bartold PM, Narayanan AS. Biology of the periodontal connective tissue: Fundamental Principles of Connective Tissue Biology. Inflammation and Wound Healing.1998; 47-69.

3. Bhatia G, Kumar A, Khatri M, Bansal M, Saxena S Assessment of the width of attached gingiva using different methods in various age groups: a clinical study. J Indian Soc Periodontol. 2015;19(2):199-202.

4. Bjorn H. Free transplantation of gingiva propria. Sweden Dental Journal. 1963; 22:684-689.

5. Sağlam M, Köseoğlu S. Treatment of localized gingival recessions with free gingival graft. European Journal of General Dentistry. 2012; 1:10-4.

6. Imano MH, Cunha EJ, Storrer CLM, Deliberador TM. A modified free gingival graft technique for gaining vertical and horizontal soft tissue augmentation. Journal of Indian Society of Periodontology. 2019; 23(1):77-80

7. Eltas A, Eltas S, Uslu M, Ersöz M. Evaluation of Patient Discomfort at the Palatal Donor Site Following Free Gingival Graft Procedures: A Randomized Controlled Clinical Trial. J Periodontol Implant Dent. 2014; 6(2):47-53.

8. Wyrębek B, Górski, B, Górska R. Patient morbidity at the palatal donor site depending on gingival graft dimension. Dental and Medical Problems. 2018; 55:153-159.

9. Wessel JR, Tatakis DN. Patient outcomes following subepithelial connective tissue graft and free gingival graft procedures J Periodontol. 2008; 79(3):425-430.
10. Ayvazyan A, Morimoto N, Kanda N, Takemoto S, Kawai K, Sakamoto Y, Taira T, Suzuki S. Collagen-gelatin scaffold impregnated with bFGF accelerates palatal wound healing of palatal mucosa in dogs. J Surg Res. 2011; 171(2):e247-e257.

11. Ehab K, Abouldahab O, Hassan, Fawzy El- Sayed K. Alvogyl and absorbable gelatin sponge as palatal wound dressings following epithelialized free gingival graft harvest: a randomized clinical trial. Clin Oral Invest. 2020; 24:1517-1525.

12. Choukroun J, Adda F, Schoeffler C, Vervelle A. Une opportunite' en paro-implantologie: le PRF. Implantodontie 2000; 42:55-62. French

13. Dohan DM, Choukroun J, Diss A, ,Dohan SL, Dohan AJ, Mouhyi J, Gogly B . Platelet-rich fibrin (PRF): A secondgeneration platelet concentrate. Part I: Technological concepts and evolution. Oral Surgery, Oral Medicine, Oral Pathology, Oral Radiology, and Endodontics. 2006; 101:e37-e44.

14. Naik B, Karunakar P, Jayadev M, Marshal VR. Role of Platelet rich fibrin in wound healing: A critical review. Journal of Conservative Dentistry.2013 ; 16(4):284-93.

15. Kulkarni MR, Thomas BS, Varghese JM, Bhat GS Platelet-rich fibrin as an adjunct to palatal wound healing after harvesting a free gingival graft: A case series. J Indian Soc Periodontol. 2014; 18(3):399-402.

16. Bahammam MA. Effect of platelet-rich fibrin palatal bandage on pain scores and wound healing after free gingival graft: a randomized controlled clinical trial. Clin Oral Invest. 2018 Dec; 22(9):3179-3188.

17. Femminella B, Iaconi MC, Di Tullio M, Romano L, Sinjari B, D’Arcangelo C, De Ninis P, Paolantonio M. Clinical Comparison of Platelet-Rich Fibrin and a Gelatin Sponge in the Management of Palatal Wounds After Epithelialized Free Gingival Graft Harvest: A Randomized Clinical Trial. J Periodontol. 2016; 87(2):103-13.

18. Dahiya P, Kamal R. Hyaluronic Acid: a boon in periodontal therapy. North American Journal of Medical Sciences. 2013; 5(5):309-315.

19. Yıldırım S, Özener HÖ, Doğan B, Kuru B. Effect of topically applied hyaluronic acid on pain and palatal epithelial wound healing: An examiner-masked, randomized, controlled clinical trial. J Periodontol. 2018; 89(1):36-45. 
20. Sharma V, Kumar A, Puri K, Bansal M, Khatri M. Application of platelet-rich fibrin membrane and collagen dressing as palatal bandage for wound healing: A randomized clinical control trial. Indian J Dent Res. 2019;30(6):881-888.

21. American Society of Anesthesiologists. ASA Physical Status Classification System. Available from: https://www. asahq.org/standards-and guidelines/asa-physical-statusclassification-system.

22. Price DD, McGrath PA, Rafii A, Buckingham B. The validation of visual analogue scales as ratio scale measures for chronic and experimental pain. Pain. 1983; 17(1):45-56.

23. Sousa F, Machado V, Botelho J, Proença L, Mendes JJ, Alves R. Effect of A-PRF Application on Palatal Wound Healing after Free Gingival Graft Harvesting: A Prospective Randomized Study. Eur J Dent. 2020;14(1):63-69.

24. Landry RG, Turnbull RS, Howley T. Effectiveness of benzydamyne $\mathrm{HCl}$ in the treatment of periodontal post-surgical patients. Research Clinical Forums. 1988; 10:105-118.

25. Wang HL, Bunyaratavej P, LabadieM, Shyr Y, MacNeil RL. Comparison of 2 clinical techniques for treatment of gingival recession. J Periodontol. 2001; 72(10):1301-1311.

26. Yen CA, Griffin TJ, Cheung WS, Chen J. Effects of platelet concentrate on palatal wound healing after connective tissue graft harvesting. J Periodontol. 2007; 78(4):601-610.

27. Shetty V, Schwartz HC. Wound healing and perioperative care. Oral Maxillofac Surg Clin North Am. 2006; 18(1):107-113.

28. Colciago A, Celotti F, Casati L, Giancola R, Castano SM, Antonini G, Sacchi3 MC, Negri-Cesi P. In vitro effects of PDGF isoforms (AA, BB, AB and $\mathrm{CC}$ ) on migration and proliferation of SaOS-2 osteoblasts and on migration of human osteoblasts. International Journal of Biomedical Science. 2009; 5(4): 380-389.

29. Djagny VB, Wang Z, Xu S. Gelatin: a valuable protein for food and pharmaceutical industries: review. Crit Rev Food Sci Nutr. 2001; 41(6):481-492.

30. Reddy S, Prasad MG, Singh S, Bhowmik N, Krishnanand P, Ashwini. N. Enhancing palatal wound healing by using platelet rich fibrin membrane as fibrin bandage. International Journal of Applied Dental Sciences. 2015; 1(4):02-04.

31. Patarapongsanti A, Bandhaya P, Sirinirund B, Khongkhunthian S, Khongkhunthian P. Comparison of platelet-rich fibrin and cellulose in palatal wounds after graft harvesting. Journal of Investigative Clinical Dentistry. 2019; 10(4):e12467. 